\title{
Fontes Orais Sobre o Teatro em Porto Alegre: Memórias de Diretores Sobre Suas Trajetórias Artísticas na Pós-ditadura
}

${ }^{*}$ Clóvis Massa

Resumo

O trabalho examina a história do teatro gaúcho das últimas décadas a partir da visão de diretores e atores que tiveram sua formação no Departamento de Arte Dramática da Universidade Federal do Rio Grande do Sul e que integraram relevantes grupos de teatro durante o processo de redemocratização do país, ocorrido a partir do final dos anos 70. A pesquisa investiga a maneira encontrada pelos núcleos para a constituição de suas poéticas cênicas, quais eram as especificidades do teatro em Porto Alegre em relação às práticas correntes do fazer teatral e como os núcleos se relacionavam com a noção de teatro político daquele período. Utiliza-se do procedimento da história oral, por meio da realização de entrevistas em profundidade, para a obtenção de narrativas sobre as trajetórias e os espetáculos considerados por eles como sendo mais relevantes, a fim de apreender a sensibilidade de cada um acerca das experiências vividas.

Palavras-chave: teatro em Porto Alegre história oral - teatro de grupo

\begin{abstract}
The paper examines the history of the theater performed in Rio Grande do Sul in the last decades from the point of view of directors and actors who had their training at the Department of Dramatic Arts of the Federal University of Rio Grande do Sul and that integrated relevant theater groups during the process of redemocratization of the country, hapenned from the late 70's. The research investigates the way found by different groups to constitute their own scenic poetics, which were the specifics of the theater making in Porto Alegre against current theater practices done and how they used to relate to the notion of political theater of that period. We use the procedure of oral history through interviews to obtain narratives of the trajectories and spectacles considered by them as the most relevant in order to apprehend the sensitivity of each one about those experiences.
\end{abstract}

keywords: theatre in Porto Alegre - oral history - group theatre 
No segundo semestre de 2012, dei início à realização de entrevistas com artistas que trabalharam em Porto Alegre e que tiveram contato, em sua formação, com o Departamento de Arte Dramática da UFRGS. A pesquisa, que contou desde o princípio com o apoio de um mestrando e dois bolsistas de iniciação científica, teve como objetivo inicial a abordagem da história do teatro em Porto Alegre, a partir das possíveis relações entre sua origens, o estado do fazer teatral no presente e as perspectivas futuras, tanto em sua dimensão artística e estética, quanto a respeito de suas relações de produção. Para tanto, optou-se pela realização de entrevistas em profundidade com o objetivo da apreensão da biografia de atores e diretores de teatro que integraram diferentes grupos locais e que participaram de fases distintas do teatro feito na cidade, em vias de que tivéssemos uma visão panorâmica sobre o fazer artístico desses sujeitos, sem abrir mão de suas subjetividades, ao identificar seus pontos de vista, ideologias e particularidades a respeito de suas próprias trajetórias.

Apresento nesse texto a primeira reflexão feita a partir da análise da série inicial de entrevistas, tendo como foco de interesse, mais especificamente, o teatro feito na transição do período de ditadura militar para o período de redemocratização política brasileiro. Nesse sentido, a delimitação sobre o teatro feito durante o processo de transição política é bastante tênue, visto que, apesar da luta pela anistia aos presos e perseguidos políticos ter mobilizado vários movimentos sociais e grupos políticos ainda em meados da década de 1970, a Lei da Anistia somente foi promulgada em 1979 ainda durante a ditadura militar e, apesar do retorno dos exilados, recebidos em clima de festividade no verão de 1979 para 1980, o processo de redemocratização ocorreu de forma lenta, gradual e restrita. Questões sobre o teor político do teatro feito em Porto Alegre nessa época de transição, sobre a poética dos espetáculos de grupos com diferentes concepções artísticas e as leituras sobre o fazer teatral do passado me interessam sobremaneira, talvez porque não se encontre, por parte da sociedade brasileira, a mesma postura que países como a Argentina e a África do Sul demonstram em relação ao resgate da memória social e à luta contra o esquecimento do que se passou naqueles anos de repressão. O pioneirismo da Argentina em relação à punição e responsabilização dos agentes do Estado responsáveis por crimes e violações cometidos durante a ditadura militar, e as formas encontradas pela África do Sul para estabelecer um novo pacto social, ao reconciliar a sociedade através da exposição da violência, e da declaração dos crimes executados por ambos os lados, representa um avanço considerável em comparação à Comissão da Verdade aprovada no Brasil, recentemente, pela Presidente Dilma Roussef, em 18 de novembro de 2011. Além disso, ainda que estudos sobre o teatro de protesto e resistência no país não sejam de todo raros, as especificidades das propostas artísticas nesse período de transição ainda carecem de ser estudadas, principalmente no âmbito local. A noção de teatro de grupo trazida aqui se refere, então, à prática continuada dos núcleos artísticos que se reúnem em torno de princípios comuns e promovem a constituição de uma linguagem específica ao seu fazer teatral.

As entrevistas foram feitas no modalidade de "história da vida artística" dos sujeitos, registradas na sede do Departamento de Arte Dramática da UFRGS. Ainda que a conversa se mantivesse aberta para cada um deles falar de si, o ponto inicial foi sempre a formação artística e o contato com o Departamento em sua trajetória. Inevitavelmente, a conexão com o período conturbado do então Centro de Arte Dramática, como era denominado o curso, surgiu em várias das entrevistas. Com a cassação e a aposentadoria compulsória de dezenas de professores da Universidade, em 1969, por motivos políticos, vários entrevistados descrevem os esforços no sentido de que o curso não fosse fechado pela falta de professores, ocasião em que os alunos se organizaram e coordenaram pesquisas sobre as tendências do teatro contemporâneo, mantendo atividades regulares durante o período de ausência dos mestres.

Surgido dentro da instituição, o Grupo de Teatro Província, criado em 1970, obteve destaque pela experimentação e pesquisa de linguagem e contrastava com a prática do Teatro de Arena de Porto Alegre, esse, por sua vez, conhecido por sua trajetória marcada pelo posicionamento engajado na oposição à censura e muitas vezes criticado pela simplicidade cênica de suas montagens. Esta oposição entre o Grupo de Teatro Província como despreocupado com as questões políticas e o Teatro de Arena de Porto Alegre como despreocupado com as questões estéticas não corresponde à realidade. Apesar de não se afirmar como núcleo engajado politicamente, a ênfase na pesquisa de linguagem do Província ocasionava às produções a exposição de contradições sociais por meio da paródia e da elaboração de metáforas que aludiam ao contexto da repressão sociopolítica do período. Por sua vez, o repertório com ênfase na discussão social do Teatro de Arena articulava as técnicas do sistema Coringa criadas e desenvolvidas pelo Teatro de Arena de São Paulo a partir de meados da década de 1960, por meio da narração coletiva, do uso da música como suporte de conceitos, do emprego de estilos e gêneros variados e da desvinculação entre ator e personagem, com o revezamento dos integrantes em vários papeis. 
Se os referidos grupos demonstram a existência de duas formas distintas do fazer teatral até meados da década de 1970, uma associada ao teatro de resistência política e outra relacionada ao teatro de experimentação, a diversidade artística do final da década, com o surgimento de variados grupos locais de teatro, resguarda a influência desses grupos pioneiros. O impacto que os espetáculos tiveram na recepção dos entrevistados, quando ainda jovens, é expresso em falas como a do diretor Paulo Flores, ex-aluno do Departamento de Arte Dramática, um dos fundadores da Tribo de Atuadores Ói Nóis Aqui Traveiz, criada em 1978, que aponta a importância de ter assistido a montagens emblemáticas do Teatro de Arena.

É' mesmo que já' Eu tinha desde minha adolescência' pré-adolescência eu tinha lembrança do cartaz de Os Fuzis da Senhora Carrar' é algo que me fascinava e que eu não assisti' mas ficou lá na minha memória com ${ }^{12,13}$ anos". Assisti a uns espetáculos de dramaturgia brasileira' que me traziam esse olhar sobre o país' mesmo com toda censura ferrenha da época' o teatro conseguia discutir umas questões importantes. Então' A Flor da Pele' da Consuelo de Castro; Um Dois Três de Oliveira Quatro". Alguns espetáculos que foram montados pelo Teatro de Arena que eu assisti e que me traziam essa visão que o teatro podia ser um instrumento para se ampliar a questão da consciência' da discussão política' da discussão social. Claro, "pessoinha" muito jovem, 16, 17 anos. Vivendo em um periodo extremamente repressivo' que não se consegue imaginar como era na época $E$ a falta de informação completa' né' toda informação era filtrada pela censura. O que sai nos jornais' os que estava nos jornais' na televisão' tudo passava por um censura prévia· (FLORES, 2012)

Ainda que a o teor político tenha sido o aspecto mais relevante em sua formação de espectador quando era adolescente, Paulo Flores destaca que a proximidade com o público nos espetáculos que assistiu fora dos teatros de configuração de cena à italiana trouxeram para ele uma novidade que será um dos princípios da poética do Ói Nóis, ou seja, as possíveis relações entre ator e espectador em seus espetáculos. Por outro lado, foi o momento político que promoveu a aproximação dos seus integrantes. Em 1977, em virtude da pressão pela reconstrução da União Nacional dos Estudantes, ocorreram vigílias com programação cultural e política que reuniram estudantes em Belo Horizonte, São Paulo e Porto Alegre. O Ói Nóis nasce nesse momento, com as pessoas que se encontravam nas passeatas, em organizações desses atos políticos culturais.

Acho que aquele grupo de pessoas' a estética passava pelo ideológico A gente não acreditava no tipo de teatro social que se fazia na época' uma forma tradicional' convencional' uma forma de organiza' ção de produção convencional' do sistema aquela' do empresário que contrata o produtor' o diretor' $o$ ator' então todas essas questões estavam em discussão Então' pra nós' a frase do Maiakovski "Não há arte revolucionaria sem forma revolucionária" estava presente nas nossas discussões. Nós queremos um teatro de transformação' ele vai ter que reinventar' ele vai ter que pesquisar formas revolucionárias que existiram nas últimas décadas' vamos se apropriar delas' vamos reinventar outras. E a questão do espaço era o segundo ponto' porque de que maneira o grupo poderia ter uma maior liberdade de criação' nem posso dizer que seria uma liberdade total de criação por que existia a censura' existia uma polícia extremamente repressiva' mas uma maior liberdade de criação' nós tendo o nosso espaço Aí a gente vai poder reinventar um teatro novo pra nós· (FLORES, 2012)

Diferentemente do momento anterior, em que havia um trânsito entre o Teatro de Arena e o Diretório Central dos Estudantes, com o oferecimento de convites de espetáculos teatrais para estudantes, o que promovia o estímulo desses a uma atuação política pela via cultural, nesse período de efervescência política na qual, os DCEs estavam investindo na propaganda política, na luta direta contra ditadura, o segundo semestre de 1977 é o auge das manifestações em Porto Alegre, de conflito com a polícia, sendo o público dos espetáculos eminentemente jovem e ligado à Universidade e a questões políticas em pauta naquele momento.

Havia uma censura muito rígida que acompanhava os espetáculos. Eles tinham direito a convites por apresentações. Tu tinha toda semana que liberar o teu espetáculo' tu fazia um ensaio' tu passava o texto pela censura' fazia o ensaio geral que a gente chamava' o último ensaio' quando tinha tudo pronto para os censores. $E$ depois da censura' tu tinha que liberar toda semana a programação' tais $e$ 
Ao surgir oficialmente em 1978, numa sede na rua Ramiro Barcelos adaptada da boate "Las Piedras", o grupo procurava sedimentar a prática de experiências com a apresentação de espetáculos em salas não-convencionais, fazendo com que pudesse, a cada montagem, reinventar o espaço da cena. Práticas como a de Richard Schechner e seu teatro ambientalista eram apenas conhecidas como referências longínquas, sendo a mais direta influência a montagem de "Gracias Señor", dirigida por José Celso Martinez Corrêa, em 1972, em que o Teatro Oficina rompeu com a distância entre ator e espectador promovendo uma interação entre atores e espectadores sob a influência da residência que fez com o Living Theatre em São Paulo, e fruto da longa excursão alternativa do grupo com a realização de happenings em várias cidades do Nordeste do país. Ao abandonar o teatro de representação e enfatizar a presentificação, a encenação se propunha a ser um ritual, deixando de ser teatro para ser te-ato. Na revista alternativa da época, Bondinho, além da descrição sobre a proposta inovadora, havia uma entrevista com o Zé Celso, sendo esse o exemplar da publicação que os integrantes do núcleo tiveram acesso. Quando o Ói Nóis surge, o diretor do Teatro Oficina de São Paulo Zé Celso está no exílio, pois ele retorna ao Brasil em meados de 1978, e quando vem a Porto Alegre, um dos lugares que Zé Celso visita é a sede do Ói Nóis Aqui Traveiz. Tais princípios, conectados ao teatro ritual proposto por Antonin Artaud em "O Teatro e Seu Duplo", fazem parte desde a origem do grupo e ocasionaram grande repercussão entre o público da cidade, ao superarem vários padrões da prática daquele momento, sendo uma proposta política que não estava no centrada no discurso verbal, mas na corporalidade dos atores.O happening e a arte da performance estão presentes desde os primeiros trabalhos, inclusive, como em "O Sentido do Corpo", uma performance organizada por um integrante que era artista plástico. Questões que hoje continuam em voga, como a expansão dos limites do teatro ou da cena em processo, em 1979 eram debatidas e experimentadas pela primeira geração do grupo, que mantinha fortes características do Teatro Pânico proposto por Fernando Arrabal, e que na montagem de "A Bicicleta do Condenado" configurava-se pela forma como os atores seminus, engaiolados, subindo e descendo em cordas, vendados ou amordaçados, cuspiam na direção do espectador e chegavam a "fornicações" e violências simbólicas. A extensa trajetória do grupo e sua ênfase no tratamento político das obras, com utilização da dramaturgia e da teoria brechtiana, torna-se complementar, com o passar dos anos, aos princípios artaudianos, recriados pelo grupo, em cenas que procuram alcançar os sentidos do espectador e que fazem parte da vertente chamada por eles de Teatro de Vivência, no qual o espectador não é um mero observador, pois se pretende dele que seja participante de uma celebração, de um acontecimento.

Tendo, Paulo Flores, abandonado a faculdade no segundo semestre do ano anterior, quando a Terreira da Tribo foi inaugurada, o seguiram dois colegas de curso, motivados pela repressão na própria instituição, que não se mostrava como espaço livre para reivindicações e posicionamentos: Roberto Oliveira e Camilo de Lélis, artistas que seguiram caminhos específicos fora do âmbito universitário na década seguinte e constituíram grupos atuantes na cidade ao longo de vários anos.

Roberto Oliveira, ator, diretor e fundador do Depósito de Teatro, foi integrante do Ói Nóis Aqui Traveiz em sua fase inicial, ainda que não tenha participado das primeiras montagens por circunstâncias pessoais, segundo ele, devido ao nascimento de seus filhos em seqüência e à necessidade de trabalhar em outras atividades para a subsistência da família. Já no terceiro espetáculo do Ói Nóis participa como ator, em “A Bicicleta do Condenado", de Fernando Arrabal, em 1978. Se a Tribo de Atuadores, atualmente, define o ator como atuador, fusão de artista com ativista político, cuja atuação não deve ficar restrita ao palco e se torna comprometida com a realidade, para Roberto Oliveira, a prática do núcleo era motivada pela oposição à ditadura, num posicionamento claro contra a censura: "Mas nisso todo mundo era. Todo jovem artista era contra toda aquela porra. E não era tão sólido e não era essa ideologia consolidada, anarquista ou com alguma conotação política, de alguma corrente política que pode haver hoje. Mas era um grupo de esquerda.” (OLIVEIRA, 2012)

$\mathrm{O}$ afastamento do grupo de contracultura se deu naturalmente, segundo Roberto Oliveira, pois sem ter dinheiro nem para o transporte, já que por vezes ia do afastado bairro do Jardim Botânico até a sede do grupo, na Avenida Ramiro Barcelos, para ensaiar, a necessidade determinou não a inserção no emprego formal, como se deveria supor, mas a aproximação com o chamado teatro infantil como forma de subsistência. O gosto por um teatro visceral, portanto, não exclui o comprometimento com a descoberta de outras formas. Essas experiências o levaram a participar de um programa infantil na televisão Guaíba com estrondoso sucesso entre as crianças, "na pele" do personagem Remendão, espécie de grande boneco brincalhão e desaforado feito de retalhos. Durante esse tempo, o pouco mas significativo contato que teve com o teatro sério foi a substituição de um 
ator na montagem gaúcha de "Rasga Coração", peça de teor político de autoria de Oduvaldo Vianna Filho, que mostra a luta dos militantes do partido comunista contra o Estado Novo e a ação integralista. Escrita em 1972, ganhadora do Concurso de Dramaturgia do Serviço Nacional de Teatro, em 1974, a montagem de estreia foi dirigida por José Renato cinco anos após sua proibição, sendo considerada emblemática do teatro de resistência e dirigida em 1985 numa montagem local pelo argentino radicado em Porto Alegre, Nestor Monasterio. Seu olhar, nesse sentido, em relação ao próprio fazer teatral, destaca a versatilidade como artista, como ator e diretor que funda posteriormente o Depósito de Teatro, trabalha simultaneamente com atores de formações distintas em espetáculos adultos, infantis e de humor, como é o caso das apresentações da Bagasexta, misto de show de humor e sátira aos programas de auditório que passou a reunir multidões de jovens uma vez por mês na sede do grupo, numa grande festa.

Eu sempre me identifiquei teatralmente com a Terreira' com aquele tipo de teatro mais de risco' mais de interatividade da plateia' com as pesquisas teatrais da Terreira' vamos dizer assim' só que durante muito tempo a Terreira foi muito sisuda pra mim' eu sentia falta do humor lá dentro' do respiro da festa' de outra coisa' das experiências então' Eu acho que uma vez eles fizeram o Hamlet Machine do Heiner Muller' e eu escrevi um negócio dizendo, "o novo velho", porque eles tinham' assim como já tava se cristalizando uma ideologia política na Terreira' estava se cristalizando uma maneira de fazer teatro, "como fazer teatro rebelde", então eles apresentavam algo pra mim no Hamlet Maquina, um negócio que era o novo' mas não era mais o novo porque já era o velho' eu já tinha visto aquilo ali há horas acontecendo dentro da Terreira: A partir de trabalhos mais novos deles' eles deram uma virada nessa jogada e estão apresentando outras coisas. (OLIVEIRA, 2012)

O ecletismo explica o envolvimento com outros grupos ao longo das décadas posteriores, tais como a Companhia Face \& Carretos, de Camilo de Lélis, na qual atuou em vários espetáculos infantis, e a Cia. Teatro Di Stravaganza, na qual participou da célebre montagem de "Decameron", de Luiz Henrique Palese, baseada na obra de homônima de Giovanni Boccaccio, realizada totalmente em italiano, que trouxe à tona o tema da peste bubônica e da sexualidade numa época de grande repercussão da expansão da AIDS, e com a qual viajou para inúmeras cidades do Brasil e fez temporadas em Buenos Aires e Montevidéu em meados dos anos 1990. Com a constituição da sede do grupo, primeiro na Av. Benjamin Constant, depois na rua Câncio Gomes, Oliveira abre caminho à docência, com o oferecimento de cursos de formação para atores e, dentre os três (ele, Paulo Flores e Camilo de Lélis), é o único que, após ter abandonado o curso de teatro, retorna à Universidade para terminar as disciplinas finais da graduação em direção teatral e depois fazer mestrado em teatro na mesma instituição. De todos, na hora das entrevistas, é o que mais naturalmente dialogou com os interlocutores, visto que demonstrava familiaridade com o local, e suas falas indicam bastante lucidez sobre sua trajetória pessoal e a de outros artistas citados com quem trabalhou e com os quais, ainda hoje, mantém proximidade, como é o caso de Camilo de Lélis, seu colega de curso nos anos 1970, com quem considera ter aprendido a dirigir pela participação em espetáculos como "Macário, o Afortunado", da Companhia Face \& Carretos.

Antes de passar à trajetória de Camilo de Lélis, devido à particularidade do seu espetáculo de maior repercussão em relação ao contexto da anistia política, abordarei o trabalho de Júlio Conte, colega que não abandonou o curso de arte dramática e que se formou quase que simultaneamente em Medicina numa época em que a instituição permitia fazer dois cursos ao mesmo tempo, sendo hoje, além de diretor de teatro, dramaturgo e ator, também psiquiatra. Oriundo de Forqueta, à época um distrito de apenas 17 quilômetros quadrados de extensão que atualmente foi incorporado como bairro da cidade serrana de Caxias do Sul, Júlio Conte conviveu desde pequeno com as atividades artísticas amadoras realizadas pelo seu pai, na comunidade de ascendência italiana, e se mudou com a família para Porto Alegre a $1^{\circ}$ de março de 1964 , um mês antes dos eventos que culminaram com o golpe civil-militar que impediu que o vice-presidente João Goulart, de posição esquerdista, assumisse o poder após o presidente Jânio Quadros ter renunciado a seu cargo. Espectador assíduo do teatro gaúcho desde jovem, em incursões ao Teatro de Arena de Porto Alegre e ao Grupo de Teatro Província, também teve a oportunidade de tomar conhecimento de montagens importantes do centro do pais, tais como "Rasga Coração", de Vianninha, em 1979, e "Pequenos Burgueses”, de Maximo Gorki, numa encenação dirigida por Renato Borghi, em 1977, quando, no primeiro ano da faculdade de Medicina, antes de entrar para o curso de teatro, percorrera de carro, um corcel, com dois colegas próximos, os quase 1200 quilômetros até São Paulo. Nesse sentido, Júlio Conte considera que, durante muito tempo, o teatro em Porto Alegre não fazia mais do que 
remontar espetáculos importantes do eixo Rio-São Paulo. Como aluno de direção, no entanto, participou de um momento significativo em que a turma da disciplina de Direção IV, oferecida um ano antes da conclusão do curso, criou cenas baseadas no convívio com as pessoas dentro do curso de teatro. Essas cenas, uma das quais representa uma situação na escada do prédio que desabou, quando uma aluna se machucou, foram ampliadas, o que resultou no espetáculo "Não Pensa Muito Que Dói”, de 1982, a partir das idéias do colega Zeca Capellini, que achava que aquele espaço de convívio serviria de excelente fonte para a criação teatral. Cabe salientar, no entanto, que talvez ele já tivesse sido influenciado pelo grupo carioca Asdrubal Trouxe o Trombone, que articulava as temáticas contemporâneas, trazendo o naturalismo e a identificação para a cena de uma maneira pop. Apesar da montagem ter grande aceitação pelos jovens, que identificavam os professores parodiados nas diversas situações, o espetáculo era muito restrito aos estudantes do curso, que conheciam as expressões e brincadeiras em torno da temática da teoria e do fazer teatral. Com o espetáculo seguinte, "Bailei na Curva", de 1983, a ideia foi comunicar a mais pessoas e escolher, como tema, algo que fosse identificado com os grupos sociais de fora do curso. A partir de improvisações, foi-se construindo a peça com referências dos atores: um, era de família com pai militar; outra, tinha tio exilado; outro, era de família operária. A metáfora de começar a peça com uma cena com as crianças brincando, no dia em o golpe de estado foi deflagrado, contextualizava a contrarevolução como sendo da ordem do dia $1^{\circ}$ de abril, Dia dos Bobos. Com uma encenação simples, usando apenas cadeiras, a narrativa segue a vida familiar, a escola, os relacionamentos amorosos e o ambiente político dos personagens desde então, até o início do processo de redemocratização. Sendo o ator Hermes Mancilha negro, começou-se a trabalhar a história com a idéia do protagonista Pedro ter sido adotado, refletindo assim a perspectiva do morto, do excluído, do exilado.

Um dia' nós estávamos quase terminando a peça' o Hermes Mancilha disse assim, "olha Júlio' tem um problema' todo mundo fala do Pedro' e não tem a cena do Pedro' daí a gente disse: "então vamos improvisar a cena do Pedro". Improvisamos a cena do Pedro e a mãe' a cena chave' quando ele vai pra guerrilha' e a Ana e a mãe' a dona Elvira' na mesma noite A gente já estava num momento de envolvimento tal no trabalho de informações' que era fácil de improvisar' tinha um background de in formações na cabeça de todo mundo. Teve um trabalho de conjunto muito intenso' e teve um trabalho individual muito intenso' por isso que enfim' acabou gerando tensão dentro do grupo' e crise e dis' cussão de quem fez o que. Por que teve coisas assim que eram um ponto único numa mente coletiva'e teve momentos que uma mente individual organizava uma mente coletiva' que sempre acontece isso' só que no jogo de vaidades' às vezes isso dá rolo. (CONTE, 2012)

Ainda que contenha elementos de um tipo de dramaturgia voltada à expressão de conflitos de geração e questões pessoais, tais como o roubo do carro do pai, a perda da virgindade, a primeira vez em que se fuma baseado, a forma como essas situações são tratadas tem como pano de fundo o processo político do país, sem escapar de retratar a singularidade dos jovens da época na cidade, seus modismos e expressões.

No processo de roteirização de uma das peças de maior repercussão do teatro gaúcho, como destaca Júlio Conte, cheio de idas e vindas, aproveitou-se muito bem os acasos, como no caso do personagem Carlos Augusto, que durante a criação do espetáculo foi feito por um jovem com características de galã, até que, depois de três meses, abandonou os ensaios e foi substituído pelo ator Cláudio Cruz: "Ai ele entrou na primeira cena, mirradinho, narigão, ai eu disse assim, "esse cara não é o Guto!”, esse é o Caco, o Carlos Augusto virou o Caco, aí mudou o personagem e toda a característica dele, ele foi fazendo ele meio desengonçado, atrapalhadinho.” (CONTE, 2012)

O diretor Júlio Conte considera que, diferentemente de “Trate-Me Leão", de 1977, o maior êxito do grupo carioca Asdrubal Trouxe o Trombone, que mostra de forma irreverente o cotidiano da juventude na década de 1970 a partir das suas vivências (e que, num rápido parênteses, havia influenciado o grupo gaúcho Ven de-sê Sonhos por meio de uma oficina que esse realiza com o núcleo carioca, em seu espetáculo mais conhecido, School's Out, de 1980, que abordava as relações entre a juventude e a repressão política simbolizada pela escola e pelos valores ultrapassados e definia os contornos da cultura jovem da época em que estão presentes o cabelo comprido, a roupa desbotada, as drogas leves e a liberdade sexual, rebeldia essa que culminava com a ação violenta dos alunos que, no final da peça, não passavam no vestibular e queimavam os livros), "Bailei na Curva" contem a universalidade e a atualidade das obras da modernidade. 
Eu brinco que eu não sei se é a última peça da ditadura ou primeira da democracia, se é a última peça da Modernidade, da esperança. As peças que tem esperança, geralmente entram pelo melodrama, ou que são muito populares, elas entram pela comedia escrachada. Ela não é uma comedia escrachada, é um drama, uma história triste, e ela é contada de um jeito que as pessoas se emocionam por que elas riem muito e depois choram, as pessoas choram, choram muito, é uma emoção contagiante no palco, quando tu vê aquele público, um negócio absurdo. A peça tem um sonho coletivo, que tem uma ambição de se inserir dentro de um contexto social baseado na esperança. A Modernidade acredita no futuro, acredita no progresso no conhecimento, na mente, nas pessoas. O pós-moderno não acredita no homem, não acredita no progresso, no encontro, não valida várias coisas que mantém a vida. (CONTE, 2012)

Dos entrevistados escolhidos para análise, Camilo de Lélis é quem, contraditoriamente, tem uma trajetória mais diversificada, na qual as representações sobre si são mais claras e, no entanto, ao mesmo tempo, à primeira vista, parece carecer de vínculo com a abordagem da pesquisa sobre o teatro na pós-ditadura. Nascido em Santa Catarina, considera que sua primeira experiência teatral foi com apenas 5 anos de idade, quando, em Videira, seus familiares, de ascendência italiana, deram vinho para ele e passou a imitar os animais do campo, numa autêntica encenação bacante. Fruto da geração de 1954, segundo ele, uma geração perdida, que não se encaixava nem com os beats nem com os hippies, testemunhou o ciclo bandoleiro de sua família, no qual um tio matou o irmão numa tocaia, motivado por um conflito amoroso, e migrou com parte da família para Porto Alegre devido às dificuldades de sobrevivência, visto que eram 11 irmãos, e se considera até hoje um caubói urbano. Em seu caminho, passou por Bagé e quando foi para a capital instalou-se na periferia e se beneficiou de uma bolsa de estudos que o permitia estudar no Colégio Rosário, instituição marista de elite em Porto Alegre. Ao sofrer bullying pelo seu jeito de se vestir, veio à tona seu lado herói bandido que, segundo ele, o faz defender sempre os mais fracos da sociedade. Ainda que desajustado na escola, tirava boas notas e entrou em discussão com o irmão que exigia que ele escolhesse a profissão de médico, então, após apanhar do irmão, foi para a casa de uma das irmãs em São Paulo. Lá, em Jaçanã, teve a oportunidade frequentar um colégio em que uma professora levava os alunos aos espetáculos teatrais, ocasião em que foi assistir, em 1969, à famosa montagem de "Na Selva das Cidades", de Bertolt Brecht, com direção de José Celso, no Teatro Oficina:

Ela se assustou' Porque ela não esperava Aquela coisa' a professora levou os meninos' e mesmo politizada como ela era' ela se assustou com o nu da Ítala Nandi que estava atrás de um filó' de um véu' não era nem esses véus atuais' era uma coisa mais rústica. Nua' ela ficou nua algum tempo'e dizia: aqui não tem homem pra trepar comigo'.. E nós' os meninos' locões! A Ítala tava num momento fulminante da carreira dela E' adorei aquilo ali (LÉLIS, 2012)

O que parece ter sido o primeiro nu total do teatro profissional brasileiro, conforme Camilo de Lélis, para ele se soma ao fato de ter sido no final dos anos 1960 e refletia um momento de intensidade política e social. No entanto, ainda que houvesse posicionamento e conscientização por parte de muitos jovens, Camilo reconhece que, com apenas quinze anos de idade, não tinha lucidez sobre isso porque sabia que, apesar da presença autoritária dos militares no poder, havia uma máscara sobre isso, e a divulgação de um milagre de desenvolvimento brasileiro. A homenagem a essa professora, que foi expulsa da escola durante o regime numa ação de retaliação e substituída sem explicações pela escola e que, segundo ele, não se sabe se foi morta, ocorre anos depois por meio da dedicatória do espetáculo sob sua direção, "Macário”, de 1991, baseado em texto de B. Traven, conforme escreveu no programa. Após desistir de ser boxeador por ter fraturado o braço num acidente de motocicleta, passou no vestibular para Enfermagem e trabalhou em vários hospitais da cidade como estagiário, mas a um semestre de terminar o curso, abandonou-o quando se sentiu, numa espécie de surto, envolvido emocionalmente pelos pacientes terminais. Como conhecia Paulo Flores da época em que estudou no Colégio Júlio de Castilhos, foi procurá-lo por achar que "ele é quem estava certo", fazendo algo mais leve e convivendo com as pessoas de uma maneira mais libertadora, em tempos de acentuada liberdade sexual dos jovens no apartamento da rua José do Patrocínio. O contato lhe rendeu a entrada no Departamento de Arte Dramática em disciplinas que realizou fazendo o chamado curso 2, proveniente de outro curso da Universidade. Após casar e engravidar sua mulher, viajou para o Nordeste entre 1978 e 80, onde, depois de se separar, acabou ficando por um tempo em Arraial da Ajuda, na Bahia, quando o lugar era inóspito ainda. Depois de ter sido agente imobiliário (alugava cabanas aos turistas), voltou para o Sul para ficar mais próximo da filha e 
tentou ingressar novamente no trabalho de enfermagem, mas sem diploma se recusou a fazer serviço de técnico de enfermagem. Depois de fazer pão para vender, tarefa que aprendeu com uma namorada judia, empregou-se no Restaurante Macrobiótico com carteira assinada, o que permitiu que retornasse às atividades artísticas. Em 1980, estreou o espetáculo infantil "O Menino do Joelho Sujo", com texto de sua autoria, primeira das peças infantis que escreve a partir de sua biografia, e que mostra a atividade de engraxate que exerceu quando criança. Ao longo de sua carreira como diretor, em seus vários trabalhos, destacam-se duas vertentes: uma, referente à montagem de textos alemães que recebem um tratamento brasileiro, por vezes regional, e outra, em colaboração com o dramaturgo Hércules Grecco, ao recriar acontecimentos históricos ocorridos no Rio Grande do Sul.

Em sua fala, encontram aspectos específicos de como sua prática retifica o trabalho continuado no teatro de grupo:

Eu acho que não é produtivo para o ator mudar de diretor' por que não é o diretor que faz o ator' ele é quem se faz sozinho. $O$ diretor ajuda' se o diretor tiver boa afinidade' boa química. Então' o fato de continuar com o mesmo diretor' propicia que ele vá se aprofundando. Porque ele' se ele muda' inclusive repete truques que o outro diretor não sabe. Se não viu' até porque esses diretores vaidosos nem vão ver outras peças. Aí o diretor não sabe se ele usa o mesmo truque É o caminho mais reto da natureza'o mais fácil· (LÉLIS, 2012)

Sua concepção de vida anarquista, identificado como sendo ao mesmo tempo xamã e profeta, determina o pensamento que tinha a prática do grupo Face \& Carretos, em distinção a outros grupos, inclusive:

Eu vou dar um exemplo pra tu ver o que é anarquista no meu entendimento' uma outra companhia que é emblemática e continua esse tempo todo' começou antes' que é a Terreira da Tribo Ela não é uma companhia anarquista' ela é uma igreja Por quê? Por que ela tem rituais' formas e uniforme' certo? E regras corporais... Isso é uma seita' Isso é uma ideologia Eu sou anarquista' eu sou contra as ideologias. Então eu faço tanto um cara yuppie' um cara bem limpo' com uma cara rapada e faço tam bém um cara detonado' eu faço o bebum. Eu faço tudo! Porque eu sou anarquista Anarquista quer dizer: sem ideologia' não é só sem governo É uma ideologia da não ideologia'Por que sem ideologia ninguém vive É uma ideologia da não ideologia Então eu posso fazer uma obra sacra do Morro da Cruz Posso trabalhar com os colonos. Posso fazer meus folhetins do Hércules Grecco. Posso fazer meu folhetim do Hercules Grecco Faço qualquer coisa: (LÉLIS, 2012)

O trabalho de pesquisa propiciou, além dos conteúdos acerca dos espetáculos considerados mais relevantes pelos entrevistados e de seu contexto artístico, no âmbito da metodologia da História Oral, a articulação entre suas visões, experiências e as representações suscetíveis de cada um. Na análise sobre o modo de expressão dos entrevistados, o discurso contundente de Camilo de Lélis a respeito de si e dos outros contrasta com a forma pausada de Paulo Flores, em seu cuidado para escolher as palavras. As falas de Júlio Conte buscam, por momentos, justificar porque talvez seja mal visto por alguns colegas por ter tomado a liderança do grupo e continuado a encenar a peça, após o término da companhia, com outras pessoas. Roberto Oliveira, tão eclético em seu caminho artístico quanto Camilo de Lélis é em sua trajetória de vida, parece enveredar com mais fluência nos meandros da contemporaneidade, ao se valer da diversidade de formas e exercer atividades em diversos grupos. Como pessoas que se conhecem há anos, beneficiam-se da intimidade própria dos grandes amigos ao expor seus juízos sem restrições e, assim, levantar caminhos de análise sobre as possíveis poéticas do teatro da pós-ditadura dos grupos de teatro de Porto Alegre. 


\section{Referências}

CONTE, Júlio. Entrevista a Clóvis Massa e Renato Mendonça. Departamento de Arte Dramática. 2012. FLORES, Paulo. Entrevista a Renato Mendonça. Departamento de Arte Dramática. 2012. LÉLIS, Camilo de. Entrevista a Renato Mendonça. Departamento de Arte Dramática. 2012. OLIVEIRA, Roberto. Entrevista a Renato Mendonça. Departamento de Arte Dramática. 2012.

Recebido em 18/02/2015

Aprovado em 20/07/2015 